This item was submitted to Loughborough's Research Repository by the author.

Items in Figshare are protected by copyright, with all rights reserved, unless otherwise indicated.

\title{
Moderate-to-vigorous physical activity, indices of cognitive control, and academic achievement in preadolescents
}

\section{PLEASE CITE THE PUBLISHED VERSION}

http://dx.doi.org/10.1016/j.jpeds.2016.02.045

\section{PUBLISHER}

(c) Elsevier

\section{VERSION}

AM (Accepted Manuscript)

\section{PUBLISHER STATEMENT}

This work is made available according to the conditions of the Creative Commons Attribution-NonCommercialNoDerivatives 4.0 International (CC BY-NC-ND 4.0) licence. Full details of this licence are available at: https://creativecommons.org/licenses/by-nc-nd/4.0/

\section{LICENCE}

CC BY-NC-ND 4.0

\section{REPOSITORY RECORD}

Pindus, Dominika M., Eric S. Drollette, Mark R. Scudder, Naiman A. Khan, Lauren B. Raine, Lauren B. Sherar, Dale W. Esliger, Arthur F. Kramer, and Charles H. Hillman. 2019. "Moderate-to-vigorous Physical Activity, Indices of Cognitive Control, and Academic Achievement in Preadolescents". figshare. https://hdl.handle.net/2134/20732. 
RUNNING HEAD: MVPA, COGNITIVE CONTROL AND ACADEMIC ACHIEVEMENT

Associations among moderate-to-vigorous physical activity, indices of cognitive control, and academic achievement in preadolescents

Dominika M. Pindus, PhD, ${ }^{1,2}$, Eric S. Drollette, $\mathrm{BS}^{3}$, Mark R. Scudder, $\mathrm{BS}^{3}$, Naiman A. Khan, PhD, $\mathrm{RD}^{3}$, Lauren B. Raine, $\mathrm{BS}^{3}$, Lauren B. Sherar, $\mathrm{PhD}^{2,4}$, Dale W Esliger, $\mathrm{PhD}^{2,4}$, Arthur F. Kramer, $\mathrm{PhD}^{5}$, and Charles H. Hillman, $\mathrm{PhD}^{3}$

${ }^{1}$ Department of Public Health and Primary Care, University of Cambridge, Cambridge, CB1 8RN, UK ${ }^{2}$ National Centre for Sport and Exercise Medicine, School of Sport, Exercise and Health Sciences, Loughborough University, Loughborough, Leicestershire, LE11 3TU

${ }^{3}$ Department of Kinesiology and Community Health, University of Illinois at Urbana-Champaign, 906 South Goodwin Avenue, Urbana, 61801 IL, USA

${ }^{4}$ The NIHR Leicester-Loughborough Diet, Lifestyle and Physical Activity Biomedical Research Unit ${ }^{5}$ The Beckman Institute for Advanced Science and Technology, University of Illinois at UrbanaChampaign, 317 Freer Hall, 405 N. Mathews Avenue, Urbana, 61801 IL, USA

Corresponding author: Dominika Pindus, ${ }^{1}$ Department of Public Health and Primary Care, University of Cambridge, Strangeways Research Laboratory, 2 Worts' Causeway, Cambridge, CB1 8RN, UK; Email: D.M.Pindus@medschl.cam.ac.uk; Telephone: +44 (0) 1223748696

Key words: Accelerometry, aerobic fitness, inhibitory control, working memory, standardized academic tests, children. Short title: MVPA, cognitive control and academic achievement Sources of funding: This study was funded in part by a grant from the Eunice Kennedy Shriver National Institute of Child Health and Human Development HD069381 to Charles Hillman and Arthur Kramer, which also funded the work of Bonnie Hemrick and Jeanine Bensken. Lauren Sherar and Dale Esliger were funded by the National Institute for Health Research (NIHR) Diet, Lifestyle \& Physical Activity Biomedical Research Unit, University Hospitals of Leicester; the National Institute for Health Research Collaboration for Leadership in Applied Health Research and Care - East Midlands (NIHR CLAHRC - EM); Lauren Raine was funded by the National Institute for Agriculture under the Illinois Transdisciplinary Obesity Prevention Program grant (2011-67001-30101); the Hatch 
RUNNING HEAD: MVPA, COGNITIVE CONTROL AND ACADEMIC ACHIEVEMENT

Project \#ILLU-971-358. The manuscript formed a part of a PhD research by Dominika Pindus funded by the School of Sport, Exercise and Health Sciences, Loughborough University. No industry relations were noted for Bonnie Hemrick or Jeanine Bensken. Conflict of interests: Neither authors nor individuals listed in the acknowledgements report any potential, perceived or real conflict of interests in relation to this manuscript.

Date submitted: $24 / 12 / 2015$ 
RUNNING HEAD: MVPA, COGNITIVE CONTROL AND ACADEMIC ACHIEVEMENT

\begin{abstract}
Objective: To assess whether preadolescents' objectively measured moderate-to-vigorous physical activity (MVPA) is associated with cognitive control and academic achievement, independent of aerobic fitness. Little evidence exists on how child's daily MVPA (a behavior) relates to cognitive control and academic achievement once differences in aerobic fitness (a physical state) are accounted for.
\end{abstract}

Study design: A sample of 74 US children ( $M_{\text {age }}=8.64$ years, $S D=.58,46 \%$ girls) were included in the analyses. Daily MVPA (min/day) was measured over 7 days using ActiGraph wGT3X+ accelerometer. Aerobic fitness was measured using a maximal graded exercise test and expressed as maximal oxygen uptake $\left(\mathrm{mL}^{*} \mathrm{~kg}^{-1} * \mathrm{~min}^{-1}\right)$. Inhibitory control was measured with a modified Eriksen flanker task (reaction time and accuracy), and working memory with an Operation Span Task (accuracy scores). Academic achievement (in reading, mathematics and spelling) was expressed as standardized scores on the Kaufman Test of Educational Achievement. The relationships were assessed using hierarchical regression models adjusting for aerobic fitness and other covariates.

Results: No significant associations were found between MVPA and inhibition, working memory, or academic achievement. Aerobic fitness was positively associated with inhibitory control $(p=.02)$ and spelling $(p=.04)$ but not with other cognitive or academic variables ( $\left.p^{\prime} s>.05\right)$.

Conclusions: Aerobic fitness, rather than daily MVPA, is positively associated with childhood ability to manage perceptual interference and spelling. Further research into the associations between objectively measured MVPA and cognitive and academic outcomes in children while controlling for important covariates needed. 
RUNNING HEAD: MVPA, COGNITIVE CONTROL AND ACADEMIC ACHIEVEMENT

\section{Abbreviations}

ADHD Attention Deficit Hyperactivity Disorder

ANL All-or-nothing load score on a working memory task

ANU All-or-nothing unit score on a working memory task

BMI Body mass index

CPM Accelerometer counts per minute

HR Heart rate

IQ Intelligence quotient

KTEA II Kaufman Test of Educational Achievement, Second Edition

MET Metabolic equivalent

MVPA Moderate-to-vigorous physical activity

OSPAN Operation Span Task (working memory task)

PCL Partial Credit Load score on a working memory task

PCU Partial Credit Unit score on a working memory task

RT Reaction time

SES Socio-economic status

$\mathrm{VO}_{2 \max } \quad$ Maximal oxygen consumption 
Physically inactive children may be missing opportunities for optimizing their cognitive and academic potential. ${ }^{1-4}$ That is, increasing children's engagement in regular, structured and sustained MVPA (namely, aerobic exercise) can benefit cognitive functions, which are implicated in self-regulation, goal directed behavior and academic achievement (i.e. cognitive control) $)^{1,2}$ Likewise, regular increases in school physical activity can benefit academic achievement. ${ }^{3-6}$ However, little evidence exists on whether children's daily, lifestyle embedded MVPA (i.e. MVPA accumulated throughout the entire day) is related to cognitive control and academic achievement.

Extant studies using objective monitoring of physical activity yield equivocal results in relation to both cognitive control and academic achievement. That is, either null ${ }^{7-9}$ or select positive associations have been observed. ${ }^{10-12}$ However, their conclusions remain limited, as these studies did not statistically control for aerobic fitness and/or intelligence quotient (IQ). ${ }^{10-12}$ More aerobically fit children perform better cognitively (i.e., have greater working memory and can better control distractions $)^{13,14}$ and academically ${ }^{15,16}$, as do those with higher intellectual ability. ${ }^{17,18}$ In one study, a positive relationship between physical activity emerged only after mediation via aerobic fitness had been considered. ${ }^{5}$ Consequently, not accounting for inter-individual differences in these variables could occlude or confound the underlying associations.

To address this limitation, we aimed to assess the associations between accelerometer measured daily MVPA, cognitive control and academic achievement in a sample of preadolescent children while controlling for aerobic fitness and IQ. We measured two aspects of cognitive control, which are most consistently related to academic achievement: inhibitory control and working memory. ${ }^{19}$ We hypothesized that: 1) greater daily MVPA would be related to better performance on measures of cognitive control and standardized tests of academic achievement (reading, mathematics and spelling); 2) cognitive control would mediate the relationship between daily MVPA and academic achievement in reading and mathematics; and 3) aerobic fitness would mediate the relationship between daily MVPA and academic achievement in mathematics as indicated by previous findings. $^{5}$ 


\section{Methods}

One hundred three children aged 7 to 9 years $\left(48.5 \%\right.$ girls; $\left.M_{\text {age }}=8.66 \pm 0.56\right)$ were recruited from seven schools in East Central Illinois, USA between June and October in 2013 and in 2014. Approximately 1800 children were reached via flyers, mailings and local events, an average of 225 responded (12.5\%) and of those, 139 (61.8\%) qualified for the study and 103 (46\%) completed measurements. The study was approved by the Institutional Review Board of the University of Illinois at Urbana-Champaign. Parents provided written consent and children provided written assent. To qualify for the study, the children had to 1) be free of neurological disorders, 2) physical disability, and 3) clinical diagnosis of Attention Deficit Hyperactivity Disorder (ADHD; as disclosed by parents; in addition, legal guardians completed ADHD Rating Scale $\left.I \mathrm{~V}^{20}\right)$. In addition, to be included the children had to: 1) have an IQ score $>85$ on the Brief Intellectual Ability of the WoodcockJohnson III Tests of Cognitive Abilities, ${ }^{21}$ and 2 ) provide $\geq 3$ days of valid accelerometer data ( $\geq 10$ hours of valid accelerometer wear). ${ }^{22}$ One child with an IQ of 84 (not a statistical outlier) was included in the analyses (the exclusion of this child's data did not change the results). After exclusions ( $<3$ valid days of accelerometer wear $(n=10),<50 \%$ accuracy on cognitive tests $(n=13)$, missing data ( $n=6$ : cognitive variables $n=4, \operatorname{ADHD} n=1$, fitness $n=1$ ), data from 74 children ( $46 \%$ girls, $\left.M_{\text {age }}=8.64 \pm .58\right)$ were analyzed. Children visited a laboratory on two separate occasions to complete neuropsychological and cognitive testing. Accelerometers were issued on one of the testing days, and returned by a parent upon completion of wear.

Standing height was measured with a Seca telescopic stadiometer model 220 (Seca, Birmingham, UK) to the nearest millimeter and weight was assessed with a Seca 769 electronic column scale (Seca, Birmnigham, UK) while children were in lightweight clothing and shoes. BMI (weight $\left.(\mathrm{kg}) *\left(\text { height }\left(\mathrm{m}^{2}\right)\right)^{-1}\right)$ percentiles were calculated based on Centers for Disease Control growth charts. ${ }^{24}$

Physical activity was measured over seven consecutive days with a triaxial Actigraph accelerometer model wGT3X+ (ActiGraph, Pensacola, FL, USA) worn on the waist at the right 
anterior axillary line on an elastic, nylon belt. Data were collected at $100 \mathrm{~Hz}$ resolution, integrated into $15 \mathrm{~s}$ epochs using ActiLife (versions 6.7.1 to 6.10.0; ActiGraph, Pensacola, FL, USA), processed with KineSoft software (version 3.3.76, Loughborough, UK) and screened following the procedures described by Sherar et $\mathrm{al}^{23}$ Non-wear was defined as 60 minutes of consecutive zero counts, allowing for 2 minutes interruptions. ${ }^{24}$ To exclude the overnight wear, the analyses were limited to data collected between 6 am and $11 \mathrm{pm}$. MVPA was defined based on age specific cut points ${ }^{25}$ (for 8 year old children) using four metabolic equivalents (METs) as a threshold. ${ }^{26}$ Sedentary time was defined as $<100$ CPM. $^{27}$

Maximal oxygen consumption $\left(\mathrm{VO}_{2 \max }\right)$ was measured during a graded treadmill test using a computerized indirect calorimetry system (ParvoMedics True Max 2400, Sandy, UT, USA). Averages of $\mathrm{VO}_{2 \max }$ and respiratory exchange ratio (RER) were taken every 20 seconds, while children walked or ran (LifeFitness 92T, Schiller Park, IL, USA). Heart rate (HR) (polar HR monitor; Polar WearLink+31; Polar Electro, Finland) and perceived exertion (children's OMNI scale ${ }^{28}$ ) were monitored throughout the test. Relative $\mathrm{VO}_{2 \max }\left(\mathrm{mL}^{*} \mathrm{~kg}^{-1} * \mathrm{~min}^{-1}\right)$ was determined by a plateau in oxygen consumption $(>2$ $\mathrm{mL}^{*} \mathrm{~kg}^{-1} * \mathrm{~min}^{-1}$ despite an increase in workload ${ }^{29}$ ) or at least one of the following: 1) a HR $\geq 185$ beats per minute ${ }^{29}$; 2) a HR plateau ${ }^{30}$; 3) RER $\geq 1.0^{31}$; and/or 4) a score of $\geq 8$ on the children's OMNI scale. ${ }^{28} \mathrm{VO}_{2 \max }$ percentiles were computed based on normative values. ${ }^{32}$

Socio-economic status (SES) was calculated using a trichotomous index based on parental reports of: 1) child's participation in free or reduced price lunch program at school, 2) the highest level of education obtained by the mother and father, and 3) the number of parents who work full time. ${ }^{33}$ Pubertal stage was assessed by parental ratings on a pictorial scale based on photographs of secondary sexual characteristic standards $\left(5\right.$ stages $^{34,35}$. Stage 1 indicates prepubertal state (no overt signs of secondary sex charactersitics) and stage 5 indicates the full mature state.

Inhibitory control was assessed with a modified Eriksen flanker task ${ }^{36}$ which measures ability to suppress distractors and attend to relevant information. Participants were asked to respond as quickly and accurately as possible with a thumb press to the directionality (left or right) of a centrally 
positioned target fish amid an array of congruous (facing in the same direction) or incongruous (facing the opposite direction) flanker fish. ${ }^{1}$ Following 40 practice trials, participants completed two blocks of 84 experimental trials with equiprobable congruency and directionality. The stimuli were 3 $\mathrm{cm}$ tall yellow fish presented focally (using Neuroscan Stim 2 software, Compumedics, Charlotte, NC) for $250 \mathrm{~ms}$ on a blue background with equiprobable inter-stimulus intervals (ISI) of 1600, 1800 or 2000 ms. Measures of mean RT, accuracy and two measures of interference control (accuracy and reaction time interference, expressed as the differences between congruent and incongruent values with higher values indicative of poorer performance) were taken. High test re-test reliability (ICC = $0.95)$ and convergent validity $(r=0.48)$ have been observed using an abbreviated version of the task. $^{37}$

Working memory was measured with the Operation Span Task (OSPAN). ${ }^{38,39}$ A trial consisted of individual words printed on a computer screen followed by a simple arithmetic problem (e.g., $1+$ $2=3$ ). Participants were instructed to read both aloud, indicate whether an arithmetic problem was correctly solved, and to write down all words in the order of presentation during a recall phase. Four blocks of four sets of trials (set size: 1 to 4 trials) were presented at random (40 trials across 16 sets). Words were presented focally on a computer screen (Neuroscan Stim 2 software, Compumedics, Charlotte, NC) for 1000 ms followed by an ISI of 1100 ms and an arithmetic problem displayed for up to $10 \mathrm{~s}$. Scoring criteria ${ }^{39}$ included scores which did (all-or-nothing credit) and did not require (partial credit) correct and sequential recall of all items in a set: 1) all-or-nothing unit score (ANU; the number of sets correct divided by the total number of sets), 2) all-or-nothing load score (ANL; the proportion of the sum of trials correct to the total number of trials), 3) partial credit unit score (PCU; the average of the summed proportions of trials correct to the set size), and 4) partial credit load score (PCL; the proportion of trials correct to the total number of trials). OSPAN tasks have high testre-test reliability $\left(r=.88^{40}\right)$ and good convergent validity $\left(r^{\prime} s=.40\right.$ to $.60^{41}$; adult data).

Academic achievement in reading, mathematics and spelling was assessed with five subtests from the Kaufman Test of Educational Achievement, Second Edition (KTEA II). ${ }^{42}$ Composite 
standardized scores $(M=100, S D=15)$ for reading (word recognition and reading comprehension) and mathematics (math concepts, applications and computation), and standardized score for spelling subscale were included. KTEA II sub-tests have very high internal consistencies, inter-rater reliabilities and internal validity $\left(r^{\prime} s=.91-.97^{42}\right)$.

Statistical analyses

Independent sample t-tests, analyses of covariance, and chi-square statistics were used to evaluate group differences in demographic, anthropometric, physical activity, cognitive and academic achievement variables, as appropriate. Within participant differences on the flanker task were assessed with Wilcoxon signed-rank test. Pearson correlation coefficients were used to inspect bivariate associations, while partial correlations (controlling for wear time) to assess relationships with MVPA. Where appropriate, variables were transformed to comply with normality. The relationships were further inspected with three sets of multiple hierarchical regression models. In minimally adjusted models outcomes were predicted from MVPA adjusting for wear time only. Partially adjusted models were additionally adjusted for covariates (e.g., age, sex, IQ, ADHD ratings, birth weight) if they were significantly related to cognitive and/or academic achievement outcomes in bivariate correlations. Fully adjusted models were adjusted for covariates as per partially adjusted models and additionally for aerobic fitness. All models were assessed for multi-collinearity and normal distribution of error terms. Where appropriate, variables were log or square root transformed to conform to the assumption of normality of distribution. IBM SPSS Statistics version 23.0.0.1 was used to conduct all the analyses. The alpha level was set at .05.

\section{Results}

No differences were noted between children who were excluded $(n=29)$ and those included ( $n=74$ ) in the study with regards to demographic (age, sex, ADHD ratings) or anthropometric (height, weight, BMI) variables, pubertal stage, aerobic fitness, percent lower or higher fit, or overweight and obese ( $p^{\prime} s \geq .09$ ). Children included in the analyses did not differ from those excluded in any of the physical activity variables (CPM, time sedentary, light PA or MVPA; $p^{\prime} s \geq .07$ ). Those 
included in the analyses had, on average, higher IQ $\left(M_{\text {incl }}=112, M_{\text {excl }}=102, t(101)=3.13, p=.002\right)$, while those excluded were more likely to come from a lower SES background $\left(O R=2.89, \chi^{2}(1)=\right.$ $5.66, p=.02)$.

Descriptive characteristics of participants stratified by sex are presented in table 1 . No significant sex differences were noted for age, anthropometric (height, weight, BMI, BMI percentile) ADHD, IQ ( $\left.p^{\prime} s \geq .29\right)$ or physical activity variables (CPM, wear time, sedentary time, MVPA; $p^{\prime} s \geq .11$ ). As expected, boys had higher relative $\mathrm{VO}_{2 \max }(t(72)=2.05, p=.044)$ but did not differ from girls on $\mathrm{VO}_{2 \max }$ percentile $(p=.52)$. No sex differences were noted for SES, overweight/obese status, or percent of higher and lower fit ( $\left.p^{\prime} s \geq .22\right)$. Girls were more likely to be classed as pre-pubertal (OR = 3.1, $\chi 2=5.64, p=.18)$. Boys were more accurate $\left(M_{\text {boys }}=83.6 \%\right)$ than girls $\left(M_{\text {girls }}=77.4 \%, t(72)=\right.$ 2.55, $p=.01$ ) on the congruent flanker condition. No further sex differences were noted in performance on either cognitive tasks or academic achievement tests ( $p^{\prime} s \geq .15$ ).

The majority of participants ( $n=64,86.5 \%)$ wore the accelerometer for at least five days, two (2.7\%), eight (10.8\%), 16 (21.6\%), 26 (35.1\%) and 22 (29.7\%) participants provided data for 3, 4, 5, 6 and 7 days, respectively. Average daily wear time was 13.3 hours (6am-11pm table 1 ). Physical activity was positively and moderately related to aerobic fitness: CPM: $r=.37, p=.001$, MVPA (log transformed): $p r=.37, p=.001$. Participants' performance on cognitive tasks and academic achievement tests are summarized in table 2. As expected, participants responded, on average, faster and more accurately on congruent than incongruent trials, mean $\mathrm{RT}_{\text {difference }}: Z=7.22, p<.001$, $r=0.59 ;$ accuracy $_{\text {difference }}: Z=-6.02, p<.001, r=.50$.

No significant partial correlations between MVPA and either cognitive or academic achievement variables were noted ( $p^{\prime} s \geq .13$ ). Aerobic fitness was negatively related to accuracy interference $(r=-.25, p=.03$ ) but not to other cognitive variables or academic achievement ( $p s \geq$ $.11)$.

Table 3 presents the summary of the results (significance levels for model ANOVAs, model $\mathrm{R}^{2 \text { s }}$ and standardized parameter estimates for MVPA and fitness, where appropriate; data for 
covariates not shown) from the minimally (adjusted for wear time), partially (additionally adjusted for covariates) and fully adjusted (additionally adjusted for aerobic fitness) regression models predicting inhibitory control, working memory and academic achievement from MVPA. MVPA was not related to either measures of inhibitory control (accuracy, mean RT or interference on the flanker task; $p^{\prime} s \geq .11$ ) or working memory (PCU, PCL, ANU or ANL scores on the OSPAN, $p^{\prime} s \geq .52$ ) regardless of the adjustment for covariates and aerobic fitness (table 3). Similarly, MVPA was not related to academic achievement in either reading, mathematics or spelling in minimally, partially and fully adjusted models ( $p^{\prime} s \geq .20$ ). Covariates explained significant proportion of variance in models predicting incongruent mean RT and interference accuracy on the flanker task, PCU on the OSPAN and academic achievement in reading, mathematics and spelling as indicated by $R^{2}$ values and significant ANOVAs for partially adjusted models (table 3). Birth weight and ADHD explained $12 \%$ of variance each in incongruent mean RT and accuracy interference ( $\left.p^{\prime} s \leq .02\right)$, while IQ and age explained $21 \%$ of variance in PCU on the OSPAN task $(p=.001)$. IQ was the strongest predictor of academic achievement, accounting for $20 \%$ to $34 \%$ of variance $\left(p^{\prime} s<.001\right)$. Aerobic fitness emerged as a significant predictor of spelling $(p=.04)$, predicting $4.6 \%$ of variance, and showed a trend for accuracy interference $(p=.06)$.

In follow-up regression models, where aerobic fitness was entered as the main predictor, it explained $6.8 \%$ of variance in accuracy interference $(6=-.26, t(71)=2.40, p=.02, F(2,71)=7.17, p=$ $.001)$ after controlling for ADHD scores $(B=-.32, t=2.99, p<.001)$ and $4.7 \%$ variance in spelling $(B=$ $-.22, t(71)=2.12, p=.04, F(2,71)=12.8, p<.001)$, accounting for IQ $(B=.48, t(71)=4.74, p<.001)$. Since no significant associations between MVPA and academic achievement variables were noted, mediation analyses were not performed.

\section{Discussion}

The main finding of the study is that aerobic fitness, but not daily MVPA, is positively related to interference control (ability to control distractions) and spelling in preadolescent children. In contrast to our hypothesis that a positive associations would exist between MVPA and cognitive and 
academic outcomes, we found no significant relationships between accelerometer measured daily MVPA and measures of cognitive control (inhibitory control and working memory) or academic achievement (reading, mathematics and spelling). Consequently, the hypotheses that cognitive control and fitness mediated relationships between MVPA and academic achievement could not be tested. This study is among the first to investigate the associations between objectively measured MVPA and multiple indices of cognitive control using sensitive computerized tasks and standardized tests of academic achievement while also controlling for directly measured aerobic fitness and other important confounders (IQ, BMI, ADHD, SES and pubertal status).

Our results in relation to aerobic fitness align with cross-sectional and experimental findings indicating a positive relationship between aerobic fitness and indices of cognitive control in children. ${ }^{1,2,14,43,44}$ Specifically, we found a selective relationship between aerobic fitness and children's ability to manage distraction, which is closely related to self-regulation. ${ }^{45,}{ }^{46}$ In turn, children's ability to self-regulate cognition, behavior and emotions can predict future vocational success, health outcomes ${ }^{47}$ and academic achievement. ${ }^{19}$ The findings further align with the evidence from RCTs on the positive effects of daily after-school aerobic exercise programs on children's cognitive control. ${ }^{1,2}$ The improvements on measures of cognitive control coincided with increments in aerobic fitness. ${ }^{1,48}$ Since aerobic fitness is posited as the main mechanism for the effects of chronic exercise on cognitive control, ${ }^{49,50}$ our findings paired with evidence from the RCTs suggest that regular aerobic exercise resulting in fitness improvements is likely needed to benefit cognition, at least with children. Higher aerobic fitness levels may positively affect cognitive performance through its positive effects on cerebral blood flow, ${ }^{51,52}$ and increases in the levels of brain-derived neurotrophic factor (BDNF). ${ }^{53}$ BDNF up-regulates synaptic plasticity, neurogenesis and angiogenesis, which support neural memory formation and learning leading to increased cognitive performance. ${ }^{53,54}$ Consequently, the increments in aerobic fitness likely contribute to small but consistent positive effect of aerobic exercise on children's cognitive control. ${ }^{1,48}$ 
Our findings indicate that aerobic fitness is positively related to an applied measure of cognition as assessed with standardized achievement test (i.e. spelling test). These findings align with previous reports of positive associations between aerobic fitness and standardized measures of achievement in spelling in Dutch ${ }^{55}$ and Northern American children ${ }^{43}$ of similar age. In contrast, Lambourne et al $^{5}$ found no associations between aerobic fitness and spelling (assessed with standardized test of academic achievement). This difference in findings could be related to the difference in covariates included in the models such as IQ. Lambourne et al ${ }^{5}$ did not control for IQ in their models. Therefore, some underlying associations might have been missed due to the interindividual variation in IQ which is strongly related to academic achievement. ${ }^{56}$ In confirmation, when IQ was excluded from our model, the association between aerobic fitness and spelling was no longer observed.

In our study, accelerometer measured MVPA was not related to cognitive control or academic achievement irrespective of aerobic fitness and IQ. Previous studies reported positive associations with some cognitive $\mathrm{e}^{10,11}$ and academic ${ }^{3,5,12}$ measures and null associations with others ${ }^{7}$ $8,10,11,57$. The discrepancy in results may be related to the heterogeneity of cognitive measures, and tested covariates. In contrast to our findings, Booth et al ${ }^{12}$ and Syväoja et $\mathrm{al}^{10}$ found significant associations between the time spent in MVPA (accelerometry) and indices of inhibitory control (selective attention, interference ${ }^{12}$ and impulsivity ${ }^{10}$ ) in English and Finnish adolescents, respectively. However no relationship was noted for working memory. ${ }^{10}$ We found no associations on either measures of inhibition or working memory using sensitive computerized tasks. Although these studies are important, as they are amongst the first to report on the associations between objectively measured daily MVPA, cognition, ${ }^{10,12}$ and academic achievement ${ }^{5,6,8,12,57}$ in young people, their conclusions remain limited, as the relative contributions of aerobic fitness and/or IQ to these relationships could not be assessed. One study which did control for both factors was also limited in its conclusions due to the constraints of the cognitive task. ${ }^{7}$ Our study contributes to these previous findings by showing that adjustment for aerobic fitness did not modulate null findings in 
relation to the associations between MVPA and either cognitive control or academic achievement. Research into the associations between objectively measured MVPA and cognitive control in young people is sparse and it is premature to state whether such a relationship exists, and if so, the nature of the relationship. Therefore, further research into these associations across childhood and adolescence while controlling for important confounders is warranted. Emergent evidence from the RCTs suggests a positive effect of physical activity interventions on academic achievement in schoolaged children., ${ }^{3,4}$ However, to make specific health and policy recommendations, further research is needed into the dose-response relationship between MVPA and both academic achievement and cognition. Such research needs to consider what dose of MVPA (in terms of mode, frequency and duration) is necessary to yield academic benefits and how such a dose may change depending on a child's baseline physical activity.

Several limitations of the current study should be recognized. First, the cross-sectional design and precludes causal inferences relative to findings on aerobic fitness and interference control or spelling, which could best be addressed through a randomized controlled trial. Second, it may be suggested that the intensity cut point used in our study was lower than cut points previously used and could have captured light physical activity as well as MVPA. However, when we performed the same analyses with a higher intensity threshold (3,000 CPM), the results also remained unchanged. Further, the majority of children in our study were tested during summer holidays, when the levels of physical activity are higher compared to autumn or winter months. ${ }^{58}$ Thus, the results may not be representative of the school year. Due to well-known limitations of accelerometry, we were unable to capture swimming (i.e., the devices were not waterproof) and cycling may not be accurately quantified (i.e., given that accelerometry is optimized for ambulatory physical activity). Therefore, accelerometry may have underestimated children's daily MVPA given that these activities are more prevalent during the summer months due to organized summer camps and fair weather.

Future research should examine the dose-response relationship between MVPA, cognitive control, and academic achievement to ascertain whether aerobic exercise (which aims to increase 
aerobic fitness), bouts of daily MVPA or specific MVPA daily volume are sufficient for cognitive and academic benefits to emerge.

\section{Acknowledgements}

We thank the participants, their families, and Urbana School District 116 for participating in the study. In addition, we thank Bonnie Hemrick and Jeanine Bensken for their assistance in recruiting study participants and the numerous undergraduate students and staff who helped with the testing of study participants. 


\section{References}

[1] Hillman CH, Pontifex MB, Castelli DM, Khan NA, Raine LB, Scudder MR, et al. Effects of the FITKids randomized controlled trial on executive control and brain function. Pediatrics 2014;134:e1063-71.

[2] Davis CL, Tomporowski PD, McDowell JE, Austin BP, Miller PH, Yanasak NE, et al. Exercise improves executive function and achievement and alters brain activation in overweight children: $A$ randomized, controlled trial. Health Psychol 2011;30:91-8.

[3] Donnelly JE, Greene JL, Gibson CA, Smith BK, Washburn RA, Sullivan DK, et al. Physical Activity Across the Curriculum (PAAC): A randomized controlled trial to promote physical activity and diminish overweight and obesity in elementary school children. Prev Med 2009;49:336-41.

[4] Fedewa AL, Ahn S, Erwin H, Davis MC. A randomized controlled design investigating the effects of classroom-based physical activity on children's fluid intelligence and achievement. Sch Psychol Int 2015;36:135-53.

[5] Lambourne K, Hansen DM, Szabo AN, Lee J, Herrmann SD, Donnelly JE. Indirect and direct relations between aerobic fitness, physical activity, and academic achievement in elementary school students. Ment Health Phys Act 2013;6:165-71.

[6] Van Dijk ML, De Groot RH, Savelberg HH, Van Acker F, P.A. K. The association between objectively measured physical activity and academic achievement in Dutch adolescents: Findings from the GOALS study. J Sport Exerc Psychol 2014;36:460-73.

[7] Pindus D, Davis RM, Hillman C, Bandelow S, Hogervorst E, Biddle SH, et al. The relationship of moderate-to-vigorous physical activity to cognitive processing in adolescents: findings from the ALSPAC birth cohort. Psychol Res 2014:1-14.

[8] Syväoja HJ, Kantomaa MT, Ahonen T, Hakonen H, Kankaanpaa A, Tammelin TH. Physical activity, sedentary behavior, and academic performance in Finnish children. Med Sci Sports Exerc 2013;45:2098-104.

[9] Hansen DM, Herrmann SD, Lambourne K, Lee J, Donnelly JE. Linear/Nonlinear Relations of Activity and Fitness with Children's Academic Achievement. Med Sci Sports Exerc 2014;46:2279-85. 
[10] Syväoja HJ, Tammelin TH, Ahonen T, Kankaanpää A, Kantomaa MT. The associations of objectively measured physical activity and sedentary time with cognitive functions in school-aged children. PLoS ONE 2014;9:e103559.

[11] Booth JN, Tomporowski PD, Boyle JM, Ness AR, Joinson C, Leary SD, et al. Associations between executive attention and objectively measured physical activity in adolescence: Findings from ALSPAC, a UK cohort. Ment Health Phys Act 2013;6:212-9.

[12] Booth JN, Leary SD, Joinson C, Ness AR, Tomporowski PD, Boyle JM, et al. Associations between objectively measured physical activity and academic attainment in adolescents from a UK cohort. $\mathrm{Br}$ J Sports Med 2013;48:265-72.

[13] Scudder MR, Lambourne K, Drollette ES, Herrmann SD, Washburn RA, Donnelly JE, et al. Aerobic capacity and cognitive control in elementary school-age children. Med Sci Sports Exerc 2014;46:1025-35.

[14] Pontifex MB, Raine LB, Johnson CR, Chaddock L, Voss MW, Cohen NJ, et al. Cardiorespiratory fitness and the flexible modulation of cognitive control in preadolescent children. J Cogn Neurosci 2011;23:1332-45.

[15] Van Dusen DP, Kelder SH, Kohl HW, Ranjit N, Perry CL. Associations of physical fitness and academic performance among schoolchildren. J Sch Health 2011;81:733-40.

[16] Sardinha LB, Marques A, Martins S, Palmeira A, Minderico C. Fitness, fatness, and academic performance in seventh-grade elementary school students. BMC Pediatrics 2014;14:1-9.

[17] Demetriou A, Spanoudis G, Shayer M, van der Ven S, Brydges CR, Kroesbergen E, et al. Relations between speed, working memory, and intelligence from preschool to adulthood: Structural equation modeling of 14 studies. Intelligence 2014;46:107-21.

[18] Deary IJ, Strand S, Smith P, Fernandes C. Intelligence and educational achievement. Intelligence 2007;35:13-21.

[19] Jacob R, Parkinson J. The potential for school-based interventions that target executive function to improve academic achievement: A review. Rev Educ Res 2015;85:512-52. 
[20] DuPaul GJ, Power TJ, Anastopoulos AD, Reid R. ADHD rating scale-IV: Checklists, norms, and clinical interpretation. New York, NY: The Guilford Press; 1998.

[21] Woodcock RW, McGrew KS, Mather N. Woodcock-Johnson III Tests of Cognitive Abilities. Rolling Meadows, IL: Riverside Publishing; 2001.

[22] Rich C, Geraci M, Griffiths L, Sera F, Dezateux C, Cortina-Borja M. Quality control methods in accelerometer data processing: Defining minimum wear time. PLOS ONE 2013;8:e67206.

[23] Sherar L, Griew P, Esliger D, Cooper A, Ekelund U, Judge K, et al. International children's accelerometry database (ICAD): Design and methods. BMC Public Health 2011;11:485.

[24] Troiano RP, Berrigan D, Dodd KW, Mâsse LC, Tilert T, McDowell M. Physical activity in the United States measured by accelerometer. Med Sci Sports Exerc 2008;40:181-8.

[25] Trost SG, Pate RR, Sallis JF, Freedson PS, Taylor WC, Dowda M, et al. Age and gender differences in objectively measured physical activity in youth. Med Sci Sports Exerc 2002;34:350-5.

[26] Harrell JS, McMurray RG, Baggett CD, Pennell ML, Pearce PF, Bangdiwala SI. Energy costs of physical activities in children and adolescents. Med Sci Sports Exerc 2005;37:329-36.

[27] Treuth MS, Schmitz K, Catellier DJ, McMurray RG, Murray DM, Almeida MJ, et al. Defining accelerometer thresholds for activity intensities in adolescent girls. Med Sci Sports Exerc 2004;36.

[28] Utter AC, Robertson RJ, Nieman DC, Kang JIE. Children's OMNI scale of perceived exertion: Walking/running evaluation. Med Sci Sports Exerc 2002;34:139-44.

[29] American College of Sports Medicine., Whaley MH, Brubaker PH, Otto RM, Armstrong L. ACSM's guidelines for exercise testing and prescription. 7th ed. New York, NY: Lippincott Williams \& Wilkins; 2006.

[30] Freedson PS, Goodman TL. Measurement of oxygen consumption. In: Rowland TW, ed. Pediatric laboratory exercise testing: Clinical guidelines. Champaign, IL: Human Kinetics Publishers; 1993. p. 91-113.

[31] Bar-Or O. Pediatric sports medicine for the practitioner: From physiologic principles to clinical applications. New York: Springer-Verlag; 1983. 
[32] Shvartz E, Reibold RC. Aerobic fitness norms for males and females aged 6 to 75 years: A review. Aviat Space Environ Med 1990;61:3-11.

[33] Birnbaum AS, Lytle LA, Murray DM, Story M, Perry CL, Boutelle KN. Survey development for assessing correlates of young adolescents' eating. Am J Health Behav 2002;26:284-95.

[34] Tanner JM. Growth at adolescence. 2nd ed. Oxford: Blackwell Scientific Publications; 1962.

[35] Taylor SJC, Whincup PH, Hindmarsh PC, Lampe F, Odoki K, Cook DG. Performance of a new pubertal self-assessment questionnaire: A preliminary study. Paediatr Perinat Epidemiol 2001;15:88-94.

[36] Eriksen BA, Eriksen CW. Effects of noise letters upon identification of a target letter in a nonsearch task. Percept Psychophys 1974;16:143-9.

[37] Weintraub S, Dikmen SS, Heaton RK, Tulsky DS, Zelazo PD, Bauer PJ, et al. Cognition assessment using the NIH Toolbox. Neurology 2013;80:S54-S64.

[38] Turner ML, Engle RW. Is working memory capacity task dependent? J Mem Lang 1989;28:12754.

[39] Conway AA, Kane M, Bunting M, Hambrick DZ, Wilhelm O, Engle R. Working memory span tasks: A methodological review and user's guide. Psychon Bull Rev 2005;12:769-86.

[40] Klein K, Fiss WH. The reliability and stability of the turner and Engle working memory task. Behav Res Methods Instrum Comput 1999;31:429-32.

[41] Kane MJ, Hambrick DZ, Tuholski SW, Wilhelm O, Payne TW, Engle RW. The generality of working memory capacity: A latent-variable approach to verbal and visuospatial memory span and reasoning. J Exp Psychol Gen 2004;133:189-217.

[42] Kaufman AS, Kaufman NL. Kaufman Test of Educational Achievement, KTEA II. 2 ed. San Antonio, TX: Pearson; 2004.

[43] Scudder MR, Lambourne K, Drollette ES, Herrmann S, Washburn R, Donnelly JE, et al. Aerobic capacity and cognitive control in elementary school-age children. Med Sci Sports Exerc 2014;46:1025-35. 
[44] Moore RD, Wu C-T, Pontifex MB, O'Leary KC, Scudder MR, Raine LB, et al. Aerobic fitness and intra-individual variability of neurocognition in preadolescent children. Brain Cogn 2013;82:43-57.

[45] Rueda MR, Posner MI, Rothbart MK. The development of executive attention: Contributions to the emergence of self-regulation. Dev Neuropsychol 2005;28:573-94.

[46] Sporer N, Brunstein JC, Glaser C. Attention control as indicator of self-regulation and its influence on scholastic achievement: Results of a longitudinal analysis. Psychologie in Erziehung und Unterricht 2006;53:1-11.

[47] Moffitt TE, Arseneault L, Belsky D, Dickson N, Hancox RJ, Harrington H, et al. A gradient of childhood self-control predicts health, wealth, and public safety. Proc Natl Acad Sci U S A 2011;108:2693-8.

[48] Davis CL, Tomporowski PD, Boyle CA, Waller JL, Miller PH, Naglieri JA, et al. Effects of aerobic exercise on overweight children's cognitive functioning: A randomized controlled trial. Res $Q$ Exerc Sport 2007;78:510-9.

[49] Etnier JL. Are we ready to prescribe physical activity to promote cognitive function? Med Sci Sports Exerc 2006;38:S29-S30.

[50] Kramer AF, Hahn S, Cohen NJ, Banich MT, McAuley E, Harrison CR, et al. Ageing, fitness and neurocognitive function. Nature 1999;400:418-9.

[51] Brown AD, McMorris CA, Longman RS, Leigh R, Hill MD, Friedenreich CM, et al. Effects of cardiorespiratory fitness and cerebral blood flow on cognitive outcomes in older women. Neurobiol Aging 2010;31:2047-57.

[52] Zimmerman B, Sutton BP, Low KA, Fletcher MA, Tan CH, Schneider-Garces N, et al. Cardiorespiratory fitness mediates the effects of aging on cerebral blood flow. Front Aging Neurosci 2014;6:59.

[53] Gomez-Pinilla F. Brain foods: the effects of nutrients on brain function. Nat Rev Neurosci 2008;9:568-78. 
[54] Gomez-Pinilla F, Feng C. Molecular mechanisms for the ability of exercise supporting cognitive abilities and coutneracting neurological disorders. In: Boecker $\mathrm{H}$, Hillman $\mathrm{CH}$, Scheef L, Strüder HK, eds. Functional neuroimaging in exercise and sport sciences. New York: Springer; 2012. p. 25-44.

[55] van der Niet AG, Hartman E, Smith J, Visscher C. Modeling relationships between physical fitness, executive functioning, and academic achievement in primary school children. Psychol Sport Exerc 2014;15:319-25.

[56] Kaufman SB, Reynolds MR, Liu X, Kaufman AS, McGrew KS. Are cognitive g and academic achievement $g$ one and the same g? An exploration on the Woodcock-Johnson and Kaufman tests. Intelligence 2012;40:123-38.

[57] LeBlanc MM, Martin CK, Han H, Newton R, Sothern M, Webber LS, et al. Adiposity and physical activity are not related to academic achievement in school-aged children. J Dev Behav Pediatr 2012;33:486-94.

[58] Kristensen PL, Korsholm L, Møller NC, Wedderkopp N, Andersen LB, Froberg K. Sources of variation in habitual physical activity of children and adolescents: The European Youth Heart Study. Scand J Med Sci Sports 2008;18:298-308. 
RUNNING HEAD: MVPA, COGNITIVE CONTROL AND ACADEMIC ACHIEVEMENT

Table 1. Mean (SD) values for participants’ demographic, anthropometric, aerobic fitness and physical activity data

\begin{tabular}{|c|c|c|c|c|c|c|}
\hline & \multirow{2}{*}{$\begin{array}{l}\text { Girls }(n=34) \\
\text { M (SD) }\end{array}$} & & \multicolumn{2}{|l|}{ Boys $(n=40)$} & \multicolumn{2}{|c|}{ Combined $(N=74)$} \\
\hline & & & $\mathrm{M}(\mathrm{SD})$ & & $\mathrm{M}(\mathrm{SD})$ & \\
\hline Age (yrs) & $8.63(.56)$ & & $8.66(.60)$ & & $8.64(.58)$ & \\
\hline SES Low $(n,[\%])$ & $8[23.5]$ & & $12[30.0]$ & & $20[27.0]$ & \\
\hline Ethnicity (White $n,[\%]$ ) & 25 [73.5] & & $23[57.5]$ & & $48[65]$ & \\
\hline $\mathrm{IQ}^{1}$ & $111.4(11.2)$ & & $111.8(12.6)$ & & $111.6(11.9)$ & \\
\hline Height (cm) & $135.2(6.64)$ & & $135.6(7.17)$ & & $135.4(6.89)$ & \\
\hline Weight (kg) & $35.0(11.0)$ & & $34.1(9.02)$ & & 34.5 (9.93) & \\
\hline BMI $\left(\mathrm{kg} / \mathrm{m}^{2}\right)$ & $18.9(4.54)$ & & $18.4(3.73)$ & & $18.6(4.10)$ & \\
\hline OW/OB (n, [\%]) & $12[35.3]$ & & $14[35.0]$ & & $26[35.1]$ & \\
\hline $\mathrm{VO}_{2 \max }\left(\mathrm{mL}^{*} \mathrm{~kg}^{-1} * \min ^{-1}\right)$ & $41.4(8.06)$ & & $45.1(7.64)^{*}$ & & $43.4(8.00)$ & \\
\hline $\mathrm{VO}_{2 \max }$ percentile & $41.6(34.1)$ & & 36.7 (31.1) & & $38.9(32.4)$ & \\
\hline & $\mathrm{M}(\mathrm{SD})$ & Range & $\mathrm{M}(\mathrm{SD})$ & Range & $\mathrm{M}(\mathrm{SD})$ & Range \\
\hline CPM & $549.6(151.9)$ & {$[328.4-925.7]$} & $561.7(167.3)$ & [285.1 - 996.7] & $556.2(159.4)$ & [285.1 - 996.7] \\
\hline Wear time (minutes/day) & 790.8(48.8) & [673.6 - 891.7] & $809.3(48.0)$ & [712.6 - 909.6] & $800.8(48.9)$ & [673.6 - 909.6] \\
\hline Sedentary (minutes/day) & $443.6(56.0)$ & [328.7 - 554.2] & $460.4(68.3)$ & [338.9 - 637.5] & 452.7 (63.1) & [328.7 - 637.5] \\
\hline LPA (minutes/day) & $262.1(40.0)$ & [143.0 - 339.7] & $255.7(34.2)$ & [200.9 - 346.6] & $258.6(36.8)$ & [143.0 - 346.6] \\
\hline MVPA (minutes/day) & $85.1(26.4)$ & [46.1 - 137.5] & 93.2 (30.6) & [45.0 - 158.7] & 89.5 (28.9) & {$[45.0-158.7]$} \\
\hline
\end{tabular}

Note. SES, socio-economic status; IQ, a composite standardized score of intelligence quotient from Woodcock-Johnson III Tests of Cognitive Abilities, Brief Intelligence Assessment $^{21}$; IQ minimum $=84(n=1)$; OW/OB, overweight or obese category defined based on the CDC growth charts ${ }^{23}$; CPM, counts per minute; sedentary time $<100$ CPM; LPA, light physical activity $\geq 100,<1638$; MVPA, moderate-to-vigorous physical activity $\geq 1638$ CPM; intensity cut points were based on age specific cut points for 8 year-olds (using a four METs threshold) developed by Freedson and first published by Trost et al ${ }^{26}$; sedentary cut point developed by Treuth e al. ${ }^{28}$ 
RUNNING HEAD: MVPA, COGNITIVE CONTROL AND ACADEMIC ACHIEVEMENT

Table 1. Performance on flanker task, OSPAN and academic achievement

\begin{tabular}{|c|c|c|}
\hline & Mdn (IQR) & Range \\
\hline \multicolumn{3}{|l|}{ Flanker Congruent } \\
\hline Mean RT (ms) & $518.6(132.8)^{\mathrm{a}}$ & [392.5 - 827.0] \\
\hline Response Accuracy (\%) & $83.3(15.5)^{\mathrm{a}}$ & {$[52.4-98.8]$} \\
\hline \multicolumn{3}{|l|}{ Flanker Incongruent } \\
\hline Mean RT (ms) & $571.8(152.5)^{\mathrm{b}}$ & [420.9 - 939.6] \\
\hline Response Accuracy (\%) & $72.6(17.0)^{\mathrm{b}}$ & {$[51.2-96.4]$} \\
\hline \multicolumn{3}{|l|}{ Flanker Interference } \\
\hline Mean RT (ms) & $49.4(44.5)$ & {$[-27.6-203.0]$} \\
\hline Response Accuracy (\%) & $8.33(11.9)$ & {$[-10.7-34.5]$} \\
\hline \multicolumn{3}{|l|}{ OSPAN } \\
\hline Mean RT (ms) & $4618.2(1555.7)$ & [2093.4 - 7354.4] \\
\hline Response Accuracy (\%) & $87.5(13.1)$ & {$[52.5-100.0]$} \\
\hline PCU & $0.60(0.28)$ & {$[.14-.97]$} \\
\hline PCL & $0.55(0.28)$ & {$[.10-.95]$} \\
\hline ANU & $0.38(0.25)$ & {$[.06-.88]$} \\
\hline \multirow[t]{2}{*}{ ANL } & $0.25(0.29)$ & {$[.03-.83]$} \\
\hline & $\mathrm{M}(\mathrm{SD})$ & Range \\
\hline \multicolumn{3}{|l|}{ Academic Achievement } \\
\hline Spelling & $110.0(23.0)$ & {$[79.0-151.0]$} \\
\hline Reading & $118.0(17.0)$ & {$[80.0-159.0]$} \\
\hline Math & $109.0(22.2)$ & {$[82.0-150.0]$} \\
\hline
\end{tabular}


Note. Superscripts a, b, denote significant within-participant differences across congruent and incongruent conditions (ps < .001); OSPAN, Operation Span Task ${ }^{39}$; PCU, partial-credit unit score; PCL, partial-credit load score; ANL, all-or-nothing load score; ANU, all-or-nothing unit score; Academic achievement was assessed with the Kaufman Test of Educational Achievement, Second Edition (KTEA II ${ }^{43}$ ) and expressed as standardized scores with the mean of 100 and an SD of 15. 
Table 3. The associations of daily moderate-to-vigorous physical activity to cognitive control and academic achievement $(\mathrm{N}=74$; except for PCU, $\mathrm{N}=72$ and ANU, N = 71)

\begin{tabular}{|c|c|c|c|c|c|c|c|c|c|c|c|c|c|c|c|}
\hline \multirow[b]{2}{*}{ Predictors } & \multicolumn{5}{|c|}{ Minimally adjusted } & \multicolumn{5}{|c|}{ Partially adjusted } & \multicolumn{5}{|c|}{ Fully adjusted } \\
\hline & $\begin{array}{l}\text { Model } \\
\mathrm{R}^{2}\end{array}$ & $\begin{array}{l}\text { Model P } \\
\text { ANOVA }\end{array}$ & B & $95 \% C I$ & $P$ & $\begin{array}{l}\text { Model } \\
\mathrm{R}^{2}\end{array}$ & $\begin{array}{l}\text { Model P } \\
\text { ANOVA }\end{array}$ & B & $95 \% C I$ & $P$ & $\begin{array}{l}\text { Model } \\
\mathbf{R}^{2}\end{array}$ & $\begin{array}{l}\text { Model P } \\
\text { ANOVA }\end{array}$ & $B$ & $95 \% C I$ & $\mathbf{P}$ \\
\hline $\begin{array}{l}\text { Model 1: } \\
\text { Incon Acc }\end{array}$ & .08 & .06 & & & & .08 & .06 & & & & .09 & .08 & & & \\
\hline $\mathrm{VO}_{2 \max }$ & & & & & & & & & & & & & .15 & $-.14 ; .57$ & .24 \\
\hline MVPA & & & -.07 & $-.12 ; .07$ & .57 & & & -.07 & $-.12 ; .07$ & .57 & & & -.12 & $-.15 ; .05$ & .33 \\
\hline $\begin{array}{l}\text { Model 2: } \\
\text { Incon } M R T^{1}\end{array}$ & .01 & .71 & & & & .13 & .02 & & & & .13 & .04 & & & \\
\hline $\mathrm{VO}_{2 \max }$ & & & & & & & & & & & & & -.06 & $-.00 ; .00$ & .61 \\
\hline MVPA & & & .08 & $.00 ; .00$ & .51 & & & .06 & $.00 ; .00$ & .61 & & & .08 & $.00 ; .00$ & .51 \\
\hline $\begin{array}{l}\text { Model 3: } \\
\text { Acc }\end{array}$ & .02 & .48 & & & & .14 & .02 & & & & .18 & .01 & & & \\
\hline Interference & & & & & & & & & & & & & & & \\
\hline $\mathrm{VO}_{2 \max }$ & & & & & & & & & & & & & $-.22 \dagger$ & $-.48 ; .01$ & .06 \\
\hline MVPA & & & -.12 & $-.10 ; .03$ & .30 & & & -.18 & -.12;.01 & .11 & & & -.10 & $-.10 ; .04$ & .43 \\
\hline
\end{tabular}

\footnotetext{
${ }^{1}$ Log transformed
} 


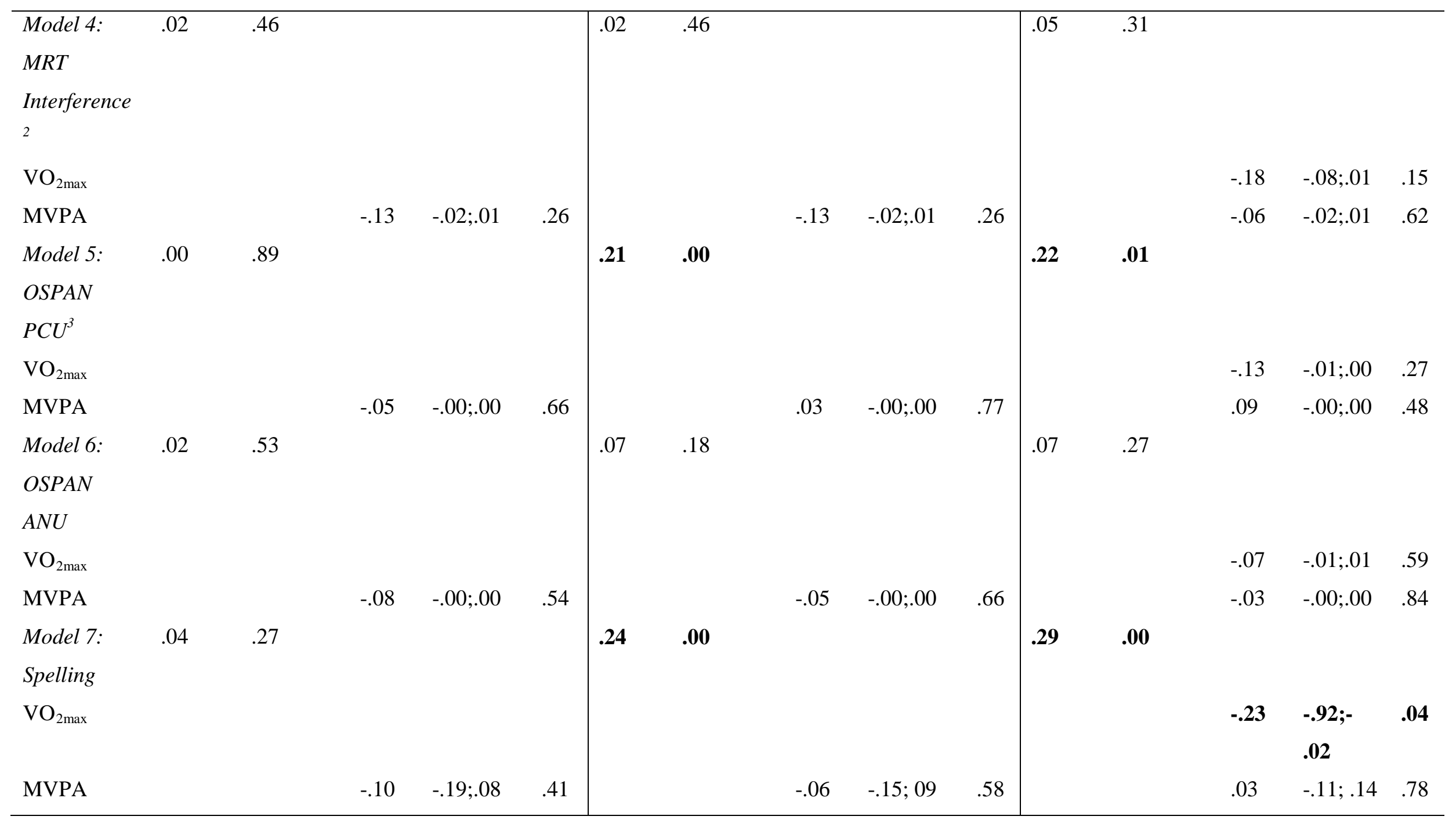

${ }^{2}$ Square root transformed

${ }^{3}$ Only PCU and ANU scores were included, as load scores were highly correlated with unit scores. 


\begin{tabular}{|c|c|c|c|c|c|c|c|c|c|c|c|c|c|c|c|}
\hline Model 8: & .04 & .22 & & & & .38 & .00 & & & & .39 & .00 & & & \\
\hline \multicolumn{16}{|l|}{ Reading } \\
\hline $\mathrm{VO}_{2 \max }$ & & & & & & & & & & & & & -.07 & $-.49 ; .24$ & .50 \\
\hline MVPA & & & -.15 & -.19;.04 & .20 & & & -.10 & $-.14 ; .04$ & .28 & & & -.08 & $-.14 ; .06$ & .46 \\
\hline Model 9: & .01 & .68 & & & & .29 & .00 & & & & .30 & .00 & & & \\
\hline \multicolumn{16}{|c|}{ Mathematics } \\
\hline $\mathrm{VO}_{2 \max }$ & & & & & & & & & & & & & -.11 & $-.64 ; .21$ & .31 \\
\hline MVPA & & & -.07 & $-.17 ; .09$ & .77 & & & -.03 & -.13;.09 & .77 & & & .01 & $-.11 ; .13$ & .90 \\
\hline
\end{tabular}

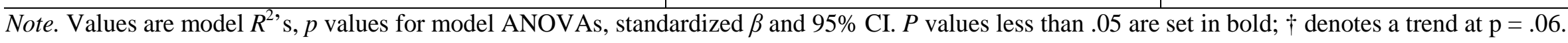

Analyses were conducted using multiple hierarchical regression models.

Minimally adjusted models were adjusted for wear time.

Partially adjusted models were additionally adjusted for: birth weight (Model 2); ADHD (Model 4); age and IQ (Model 5); birth weight and IQ (Model 6); IQ

(Models 7-9).

Fully adjusted models were adjusted as in partially adjusted models and additionally for aerobic fitness. 